\title{
Pearl Millet (Pennisetum glaucum L.) Breeding for Adaptation and Performance Under Drought Condition: Review
}

\author{
Dawit Merga \\ Ethiopian institute of Agricultural Research, Jimma Agricultural Research Center, P.O. Box 192, Jimma, \\ Ethiopia
}

\begin{abstract}
Drought stress is one of abiotic factor that threat crops economic part directly and indirectly; hence, result great yield losses in the world and become predominant cause for food security problem especially in developing countries. Pear millet is staple food crop used in different countries. It is widely produced around drought-prone arid and semi-arid regions where inter and intera seasonal rainfall variation of the areas become bottleneck for pear millet production. Thus, the current review conducted to understand pearl millet breeding for adaptation and performance under drought condition. From gene point of view crops drought resistance mechanism grouped in to drought escape, drought avoidance and drought tolerance. In all these three mechanisms crops express different control characteristics to overcome drought stress problem. Plants can use more than one mechanisms at same time based on regulators gene they posses for drought tolerance. Pear millet has huge noble traits such as rapid phonological development (early flowering which enables to escape), plasticity growth characteristics (tillering), deep and wider spread root growth and high water use efficiency those attribute for its adaptation and performance under drought stress. Both conventional and molecular breeding methods had being utilized and also currently under utilization for pear millet improvement for drought tolerance. Better performing genotypes selection and hybridization done conventionally and crosses were showed $66 \%$ heterosis over best parents in grain yield under stress; whereas marker assisted selection of QTL used for transfer of drought tolerant gene from drought tolerant genotype to drought susceptible genotype but, has good agronomic performance done using molecular breeding method. Hence, over 30\% high yielders variety developed for drought threatens environments.
\end{abstract}

Keywords: Breeding method, drought stress, early flowering, Pear millet and tiller

DOI: $10.7176 / \mathrm{JEES} / 10-4-01$

Publication date: April $30^{\text {th }} 2020$

\section{INTRODUCTION}

Pearl millet (Pennisetum glaucum L.) is a staple food crop which is grown almost entirely under rain fed conditions. Mostly it is produced around hot, drought-prone arid and semi-arid regions in Africa and south Asia (FAO and ICRISAT, 1996). Inter- and intra seasonal variation in rainfall in these regions is often one of the most important environmental factors limiting pearl millet productivity (van Oosterom et al., 1996a, b). It is grown principally for grain production but is also valued for its fodder, the importance of which has been increasing in recent years. Pearl millet is grown in areas with very limited rainfall (300-500 $\mathrm{mm}$ in the majority of cases), where crops such as maize or sorghum are very likely to be unsuccessful in most years. Thus, pearl millet is a essential component of the food security of the rural poor in dry areas.

Although drought stress can occur any time during the crop cycle, terminal stress (flowering through grain filling) is more damaging to the productivity of the crop than stress at the vegetative or pre flowering reproductive stages (Mahalakshmi et al.,1987). Because of pearl millet's asynchronous tillering behavior and rapid growth rate allow it to recover rapidly from intermittent drought stress during the early stages of plant development, but provide no advantages under unmitigated terminal drought stress.

Improving the adaptation of pearl millet to terminal drought-stress environments is therefore a major objective for breeding programmes aimed at improving both the crop's productivity and its yield stability. It has been suggested that the efficiency of breeding for stress environments could be enhanced if plant attributes that confer yield advantages in such environments could be identified and used as selection criteria (Ludlow and Muchow, 1990 and Fussell et al., 1991).

However, traits that provide a consistent yield advantage across variable water deficit environments have been difficult to identify and use in breeding programs (Richards, 1996 and Turner, 1997). Moreover, whole-plant response to drought stress is a complex process conditioned by a number of component responses that both interact and differ in their individual responses to the intensity and duration of water deficits, making it difficult to isolate individual traits with major effects on tolerance. In recent years, developments in molecular-marker technologies and their use in quantitative trait locus (QTL) analysis have provided effective new opportunities for the study of plant responses to the environment problem like drought condition (Frova et al., 1999 and Quarrie et al., 1999).

Molecular-marker breeding method provides opportunities not only to identify QTLs (and their functions) that determine complex phenotypes such as drought tolerance (Prioul et al.,1997), but also to improve greatly the efficiency of genetic improvement by facilitating the introgression of desirable traits through the use of linked 
markers (Tanksley,1993 and Mohan et al.,1997). An additional difficulty in genetically improving drought tolerance is the lack of a clear measure of drought tolerance or sensitivity. Although a number of (mainly shortterm) physiological parameters have been proposed as indicators of tolerance to drought stress (Turner, 1997), it has not been possible to relate these clearly to differences in grain yield under stress conditions (Bidinger and Witcombe, 1989). For plant breeders, tolerance has a meaning only if it gives greater yield or stability performance in yield under stress. Grain yield itself has limitations as an index for stress tolerance, as grain yield in a particular drought environment is influenced not only by genetic differences in drought tolerance, but also by differences in time to flowering (drought escape) and differences in yield potential (Bidinger et al., 1987a). In terminal drought stress, the combined effects of phenology and yield potential can account for as much as $50 \%$ of the variation in pearl millet grain yield. As a result of these effects, the most-effective means of improving pearl millet's grain yield in terminal stress environments should be to incorporate specific traits (or responses to stress) that improve the tolerance of terminal stress into high yielding genotypes of Pearl millet or appropriate crop duration (Fussell et al., 1991).

Grain yield performance itself is not a simple trait but is conditioned by a number of morphological and physiological processes. Sensitivity to post-flowering drought stress in pearl millet is often characterized by reduced grain filling and reduced numbers of grains per panicle, which result reduction in grain yield. Although genetic variation in the expression of these traits in terminal drought-stress environments exists in the available pearl millet germplasm (Bidinger et al., 1987b), the inheritance of such variation and the interactions of its various components in determining grain yield in variable moisture deficit environments are not well understood. Therefore; the objective of this review is to understand pearl millet breeding for adaptation and performance under drought condition.

\section{LITERETURE REVIEW}

\subsection{Ecological description of Pearl millet growing areas}

More than $95 \%$ of the world's millet crop is grown in Africa and South Asia, predominantly in the SahelianSudanian zones of West Africa and in the semiarid regions east and southeast of the desert in India. The areas of adaptation of the species are clearly defined by the mean annual rainfall isohyets of 200-600 $\mathrm{mm}$ in both countries. These zones are generally characterized by short rainy seasons (2-4 month), high mean temperatures, and high potential evapo-transpiration rates, arid shallow and sandy soils (Kowal and Kassam, 1978). Hence, the inter- and intra seasonal inconsistency in available soil moisture of Pearl millet growing areas is the major vulnerability to its production. Rainfall is erratic as well as low and the water-holding capacity of soils is typically low to moderate; thus, limiting the possibilities of buffering rainfall fluctuations with stored soil moisture (Bidinger, 1981).

\subsection{Importance of Pearl millet in the Human diet}

Like other Asian and African countries, in Ethiopia Pear millet is widely produced in low land areas or drought prone areas. As the crop grows in a short period of time, mostly used for food in rural areas; hence, it is well known cereal crop used for poverty escape until relatively long lifecycle crop reached for harvest to be used for consumption. Also most community that have low income prefer it for food because its price on local market is less relative to other cereals like maize, wheat, Tef (Eragrostis tef) and Sorghum. In Ethiopia, most of the time people don't use Pear millet sole for food for instance during they make Ingera (Buddeena) (favorite food in Ethiopia) they mix much powder of Pear millet with some powder of Tef. This is very important to make very good quality Ingera (Buddeena) relative to using sole Pear millet. Additionally, Pear millet plays central role in preparation of local alcohols like Tella (Farsoo) and Haraqe which are locally produced in Ethiopia and mostly preferred beverage by Ethiopian; thus, used as income source in rural areas and towns.

Concerning nutritional quality, pearl millet is at least equivalent to maize and generally superior to sorghum in protein content and quality, protein efficiency ratio (PER) values, and metabolizable energy levels. Pearl millet does not contain any condensed polyphenols such as the tannins in sorghum that can decrease digestibility. Although it contains 35\% more lysine than sorghum, it is deficient in essential amino acids, (Rooney and McDonough, 1987). Pearl millet grain contains 5-6\% oil (Jambunathan and Subramanian, 1988) and is also rich in important micronutrients such as iron and zinc. Among all cereals, it is the cheapest source of energy, protein, iron, and zinc which make pearl millet the major contributor to protein, iron, and zinc intake in the regions where it is produced.

\subsection{Mechanisms of drought tolerance of plants}

In genetic sense, the mechanisms of drought resistance can be grouped in to three categories. These are drought escape, drought avoidance and drought tolerance (Levitt, 1972). However; crop plants use more than one mechanism a time to resist drought (Gaff, 1980). Drought escape is defined as the ability of plants to complete its life cycle before serious soil and plant water deficits develop. This mechanism involves rapid phonological development (early flowering and maturity), developmental plasticity (variation in duration of growth period 
depending on the extent of moisture deficit) and preanthesis assimilation to grain (Turner, 1979). Drought avoidance is the ability of plants to maintain relatively high tissue water potential despite of a shortage of soil moisture, where as drought tolerance is the ability of plant to with stand water deficit with low tissue water potential. The responses of plants tissue to water deficit determine their level of drought tolerance.

Drought avoidance is performed by maintenance of turgor through increased rooting depth, efficient root system and increased hydraulic conductance and by reduction of water loss through reduced epidermal absorption of radiation by leaf rolling and folding (Begg,1980) and reduce evaporation area (leaf area) (Turner and Aust, 1986). Plants under drought condition survive by doing a balancing act between maintenance of cell turgor and reduction of water loss (Shashidhar et al., 2000). This mechanism could be done through osmotic adjustment (a process which induce solute accumulation in to cell) increase in cell elasticity and decrease in cell size and desiccation tolerance by protoplasmic resistance.

\subsection{Adaptation and Performance of Pearl millet under drought}

Drought is the major constraint to pearl millet as it is grown in the drier semiarid and arid regions. However, adaptive evolution and natural selection made Pearl millet relatively the most drought and high temperature tolerant among other cereals. Traditional landraces from drier regions are good sources for breeding drought tolerance (Kusaka et al., 2005). Although, the yield potential of many of the landraces is lower as compared to improved cultivars, genes for drought tolerance in the landraces can be utilized to combine with high yield potential (Yadav et al., 2000).

The growth potential of any crop species is a function of its growth rate and the length of the growth cycle. This is obviously habituated by the agronomic potential where it is grown (relating to water, light, and nutrients). In general, Pearl millet is rarely grown in areas having high agronomic potential. It is almost in variably grown in low rainfall areas (Van Oosterom et al., 1996a, b) and under marginal fertility which in fact, results in an incomplete use of the available water (Paynev et al., 1990). Thus, environmental factors are usually the main limitations to its growth potential. Even under favorable conditions, Pearl millet tends to have a shorter crop cycle than other cereals because it has a "built in" drought escape mechanism (early flowering) inherited from its wild progenitors, having evolved in semi-desert environments with adapted short life cycles. Therefore, pearl millet is short cycled, has a short grain-filling period and has small seed sizes. Its growth potential is no match for other longer-duration cereals growing in favorable environments. Yet, it enjoys a high crop growth rate that confers a fairly high growth potential under optimal conditions (Begg, 1965), relating in particular to its being a C4 plant, with a large leaf area index (LAI) due to its erect type (Craufurd and Bidinger, 1989), and high radiation use efficiency (RUE) (Squire et al., 1987). The maximum RUE recorded ranges from $2.5 \mathrm{gMJ}-1$ to 4.0gMJ-1 (Squire et al., 1987; Ram et al., 1999).

\subsection{Pearl millet characteristics enhance performance under drought 2.5.1Tillering and developmental flexibility}

Pearl millet develops primary tillers, and then secondary tillers from the primary ones, about every $45-50{ }^{\circ} \mathrm{C}$ days (base temperature of $10^{\circ} \mathrm{C}$ ). Because of high tillering ability and the length of the period between floral initiation and flowering is similar, plants have tillers at all stages of apical development at all times (Craufurd and Bidinger, 1988). Also based on the emergence place from main shoot of pearl millet tiller can be basal and nodal tillers which are emerged from main shoot at different time (Van Oosterom et al., 2002)(Figure1). This developmental plasticity/fluctuation allows pearl millet to compensate for potential failure of the main and primary tillers in the case of arid and semi- arid drought season. The secondary tillers would, to a large extent, compensate for the yield loss on the main tillers by a larger number of them developing a panicle, as long as the relief from mid-season drought makes sufficient water available for the secondary tillers to reach maturity (Mahalakshmi and Bidinger, 1985). Hence, due to its natural plasticity characteristics, pearl millet is often considered as not affected very much by mid-season drought. 


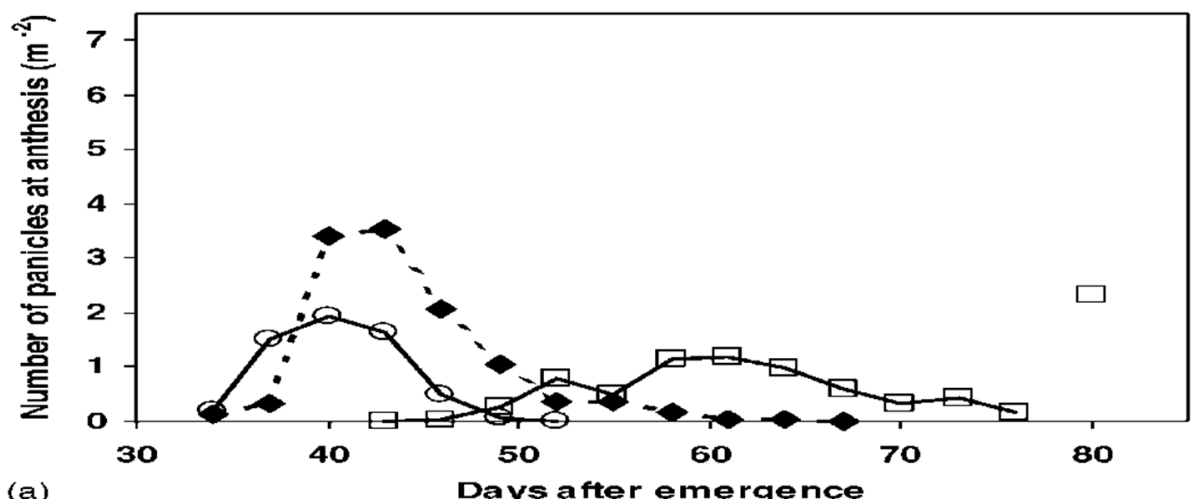

(a)

Days after emergence

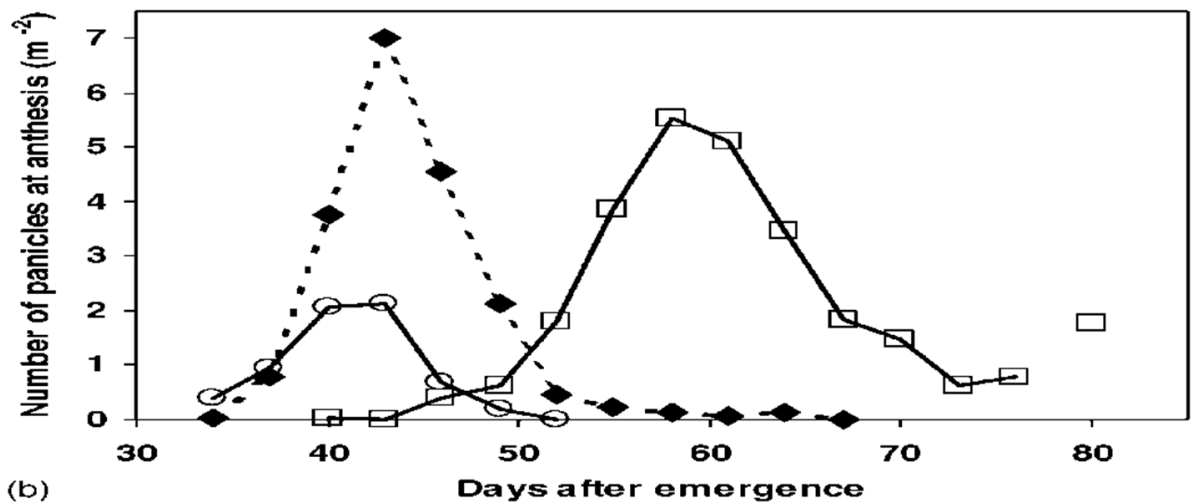

Figure 1. The number of panicles per square meter reaching anthesis at a certain number of DAE at Patancheru rainy season 1995 for (a) RCB-IC 911 and (b)WRajPop for main shoot (o-o), basal tillers

$(-8$ ) and nodal tillers ) Panicle numbers are pooled for 3-day intervals. Nodal tiller numbers at 80 DAE represent panicles for which the anthesis date is not known (van Oosterom et al., 2002).

Nodal tillers on the main shoot stared to appear one week earlier to anthesis of the main shoot panicle and they reach $250.300{ }^{\circ} \mathrm{C} \mathrm{d}$ (nearly 3 weeks) after anthesis of the main shoot panicle. Most of the period between emergence and anthesis of nodal tillers; thus, coincides with the period between the end of leaf growth and the start of grain filling of the main shoot (van Oosterom et al., 2002). The basal tillers appear start around $150{ }^{\circ} \mathrm{C} \mathrm{d}$ (after one week) after emergence of main shoot and reached anthesis 2-4 days later than the main shoot where as difference between main shoot and basal tillers in the standard deviation for anthesis were minor under optimum condition.

\subsubsection{Flowering time}

In most crops, matching plant phenology with the stress environment is a key factor in adaptation to drought. Flowering time, a so called "drought escape mechanism," is the major component of pearl millet's adaptation to water scarce environments (Bidinger et al., 1987a) as a result of its earliness flowering. Therefore, earliness is an important drought escape attribute of pearl millet and is, indeed, a major component of genotype by environmental interaction. For instance, in the case where the rains stop early, a one week difference in the time to flowering between two genotypes brings about a $30 \%$ reduction in the grain-filling period and gives the early cultivar more chance to escape drought stress, where as the late cultivars likely to suffer the stress before or during reproduction. In line with this, Bidinger et al. (1987a) authenticated that about 50\% of yield variation under drought stress conditions could be explained by differences in the yield potential of genotypes and their flowering time.

In West Africa, the sensitivity of pearl millet to the photoperiod (Clerget et al., 2004) is a way that it has evolved to "trigger" an escape mechanism, since it appears that the timing of flowering is closely related to the end of the rainy season. On the other hand, pearl millet flowers "on time" to ensure that it can complete its maturation cycle with the remaining soil moisture (Kouressy et al., 1998). Any genotype with delayed flowering may be exposed to serious stress conditions during its reproduction phase.

Panicle harvesting index is a particularly effective variable for post-flowering stress, because the mass of the structural parts of the panicle (which complete their growth prior to flowering) is largely unaffected by stress, whereas the mass of grain is significantly affected by both floret abortion and reduced grain filling (Bidinger and Mukuru, 1995). Early flowering genotype can perform more than tolerant genotype next to genotype under nonstress condition (Table 1). Also, early flowering genotypes showed better performance in grain per panicle, single mass grain, total grain mass and total panicle mass next to non-stress condition, but greater than tolerant genotypes. 
Table 1. Consequences of different levels of terminal stress tolerance on pearl millet panicle components and panicle harvest index (PNHI) (Source- Bidinger, 2002)

\begin{tabular}{|l|l|l|l|l|l|l|}
\hline $\begin{array}{l}\text { Genotype level of } \\
\text { tolerance }\end{array}$ & $\begin{array}{l}\text { Panicle structural } \\
\text { part(g) }\end{array}$ & $\begin{array}{l}\text { Grains per } \\
\text { panicle (no.) }\end{array}$ & $\begin{array}{l}\text { Single mass } \\
\text { grain (g) }\end{array}$ & $\begin{array}{l}\text { Total } \\
\text { grain } \\
\text { mass (g) }\end{array}$ & $\begin{array}{l}\text { Total } \\
\text { panicle } \\
\text { mass (g) }\end{array}$ & $\begin{array}{l}\text { PNHI } \\
(\%)\end{array}$ \\
\hline $\begin{array}{l}\text { Non-stress } \\
\text { conditions }\end{array}$ & 5.0 & 1500 & 0.0100 & 15.0 & 20.0 & 75 \\
\hline $\begin{array}{l}\text { Escape: early } \\
\text { flowering }\end{array}$ & 5.0 & 1500 & 0.0085 & 12.8 & 17.8 & 72 \\
\hline Tolerant & 5.0 & $1350(-10 \%)$ & $0.0085(-15 \%)$ & 11.5 & 16.5 & 70 \\
\hline Intermediate & 5.0 & $1200(-20 \%)$ & $0.0070(-30 \%)$ & 8.4 & 13.4 & 63 \\
\hline Susceptible & 5.0 & $1200(-20 \%)$ & $0.0050(-50 \%)$ & 6.0 & 11.0 & 55 \\
\hline
\end{tabular}

\subsubsection{Rooting ability}

Pearl millet is known to be deep and profusely rooted, with the ability to match it's rooting to water availability in a very plastic manner, leading to a highly varying root growth to shoot growth ratio, depending on the intensity of water limitation (Squire et al., 1987). During the vegetative period, root growth is very abundant, but little is known about root growth during the post anthesis period, though it has been reported that it continues well into grain-filling in long duration (Do et al., 1989). Root penetration rates between 3.5 and $4.5 \mathrm{~cm}$ day-1 have been reported in sandy soils (AzamAli et al., 1984). Root depth is dependent on the season length of the cultivar, and can be as deep as $3 \mathrm{~m}$ in long-duration varieties, in contrast to only $140 \mathrm{~cm}$ in short-duration cultivars (Chopart, 1983). Lateral root spreading is also a major feature of pearl millet, with the soil volume exploration at low planting density being as much as $6 \mathrm{~m}^{3}$.

It is often assumed that water uptake and, consequently, water limitation is what limits pearl millet production in a low rainfall environment. However, it has been shown that water may not be the most limiting factor, at least in the sandy soils, where substantial water storage and drainage have been found below the deep root zone (Payne et al., 1990). This may not be the case in all soils where pearl millet is grown. In fact, roots appear to play an important role in pearl millet genotypes that differ in the presence or absence of a major terminal drought tolerance QTL (Vadez et al., 2005).

\subsubsection{Water use efficiency}

Being a $\mathrm{C} 4$ plant, pearl millet already has high transpiration efficiency (TE). However, it seems that the major strategy of pearl millet is to maximize carbon fixation as long as water is available. Therefore, stomata movements adapt in such a way that the transpiration rate is kept as high as possible (Squire, 1979). It also appears that stomata are sensitive to the vapor pressure deficit (VPD), particularly during the pre-flowering stage, this being related to differences in the abscicic acid (ABA) content of the leaves (Henson and Mahaklakshmi, 1985).

At the plot level, water use efficiency (WUE) values of $300-400 \mathrm{~kg}$ biomass ha- $1 \mathrm{~cm}-1$ water have been reported as summing a full ground cover (LAI > 3-4) (Singh and Singh, 1995). Under low planting density, the WUE usually drops to the range $50-150 \mathrm{kgha}-1 \mathrm{~cm}-1$, mostly because of an increased evaporation component (Payne, 1997).

\subsection{Breeding for adaptation and performance under drought}

The overall goal of a breeding programme for drought stress is, ultimately, an improved genetic yield, or a more stable yield, under drought conditions. Latter, Vincent et al. (2012) reported that the stabilization of yield across environments in drought-prone areas is very important. There are different ways to assess what is commonly called "drought tolerance," and this depends mostly on how close the assessed trait/parameter is from the final target an increased genetic yield (Vincent et al., 2012).

For pearl millet, it was assumed that grain yield can be improved under water limited environments if specific traits and responses associated with drought tolerance can be identified and incorporated into elite high-yielding genotypes of appropriate crop duration (Bidinger et al., 2000). The QTL-mapping approach is ideal to meet such objectives as it can both identify individual genetic factors associated with a specific response and monitor the incorporation of the identified factors into the breeding programmes. The objective of using mapping-population progenies, based on commercially important hybrid parents, is to improve the drought tolerance of the parents so that the popular hybrids produced by them will have greater tolerance to drought (Yadav et al., 2002).

\subsection{Breeding methods used in Pear millet improvement}

\subsubsection{Conventional breeding method}

This approach was initially used to select genotypes achieving a high PNHI under terminal drought conditions. PNHI was initially tested in hybrid parent breeding, where it was used as a selection criterion by the following procedure(Vincent et al. (2012): Conduct bidirectional selection for combining ability for high and low PNHI in replicated potential maintainer $(B)$ and restorer $(\mathrm{R})$ line test cross nurseries (three testers each) grown in managed 
terminal drought stress environments (Kramer, 1980). Cross parents selected for high and low PNHI under stress conditions on three different $\mathrm{A}$ or $\mathrm{R}$ line testers from those used in the original test cross nurseries in which selection was carried out. Vincent et al. (2012) evaluate these test crosses for general combining ability (GCA) for PNHI, grain yield and yield components, in both fully irrigated control environments and in managed stress environments. Hence, the author reported that in both experiments, the dissimilarities between the high and low PNHI selections in the irrigated environments were small and generally not statistically significant; however, the differences in the terminal stress environment between the high and low selections were statistically significant and of a greater magnitude under stress conditions. For instance, the combining ability of high PNHI selections was greater that of the low PNHI selections by approximately 5-8\% for PNHI, by $9-13 \%$ for grain yield, and by 6-7\% for seed mass (Vincent et al. (2012).

Conventional breeding efforts have been implementing starting from earlier to yet in order to improve Pear millet performance under stress; for instance Yadav (2008) crossed four exotic elite with three landraces of Pear millet that possess different reaction to drought stress, and evaluated the performance of parents with their progenies under non stress and stress conditions using grain yield and biomass traits (Table2). Hence, the author authenticated the performance of most progenies over their parents in both grain yield and biomass under stress and non stress; also, in addition to realizing the availability of heterosis in drought tolerance in both traits, almost all the crosses showed superior record over both parents under stress than non stress in grain yield. The landraces and exotic elites showed 16.7 to $22.5 \mathrm{~g} / \mathrm{m}^{2}$ and 13.9 to $22.6 \mathrm{~g} / \mathrm{m}^{2}$ in grain yield performance under stress respectively; whereas, 19.4 to $37.5 \mathrm{~g} / \mathrm{m}^{2}$ recorded by crosses which exceeded high performed of both parents over $66 \%$ in grain yield performance under stress.

Table 2: Grain yield and biomass under non-drought and drought stress environments of three Pearl millet landraces, four exotic populations and twelve crosses (Yadav, 2008)

\begin{tabular}{|c|c|c|c|c|c|c|}
\hline \multirow[t]{2}{*}{ Genotypes } & \multicolumn{3}{|l|}{ Grain yield } & \multicolumn{3}{|l|}{ Biomass } \\
\hline & Non stress $\left(\mathrm{g} / \mathrm{m}^{2}-1\right)$ & $\begin{array}{l}\text { stress }\left(g / m^{2}-\right. \\
1)\end{array}$ & $\mathrm{S}^{*}$ & Non stress $\left(\mathrm{g} / \mathrm{m}^{2}-1\right)$ & $\begin{array}{l}\text { stress }\left(g / \mathrm{m}^{2}-\right. \\
\text { 1) }\end{array}$ & $\mathrm{S}^{*}$ \\
\hline Landrace 33 & 193.5 & 22.5 & 1.01 & 767.3 & 239.3 & 0.98 \\
\hline Landrace65 & 168.9 & 21.5 & 1.00 & 645.9 & 225.7 & 0.92 \\
\hline Landrace 85 & 158.8 & 16.7 & 1.02 & 787.4 & 195.8 & 1.07 \\
\hline Average $\mathrm{S}^{*}$ & & & $1.01 \mathrm{a}$ & & & $0.99 a$ \\
\hline ICMP89410 & 178.8 & 20.1 & 1.01 & 740.9 & 242.4 & 0.96 \\
\hline ICMP96132 & 238.5 & 10.2 & 1.09 & 683.4 & 131.7 & 1.15 \\
\hline ICMP93191 & 240.6 & 22.6 & 1.03 & 810.2 & 173.2 & 1.12 \\
\hline MCNELC & 224.7 & 13.9 & 1.07 & 805.5 & 194.4 & 1.08 \\
\hline Average $\mathrm{S}^{*}$ & & & $1.05 \mathrm{~b}$ & & & $1.08 \mathrm{~b}$ \\
\hline $33 \times$ ICMP89410 & 235.1 & 36.8 & 0.96 & 989.3 & 283.0 & 1.01 \\
\hline 33 x ICMP96132 & 213.8 & 22.6 & 1.02 & 897.9 & 202.7 & 1.10 \\
\hline $33 \times$ ICMP93191 & 271.7 & 25.7 & 1.03 & 900.5 & 208.0 & 1.09 \\
\hline $33 \times$ MCNELC & 187.8 & 19.4 & 1.02 & 749.2 & 276.9 & 0.90 \\
\hline $65 \times$ ICMP89410 & 266.7 & 34.7 & 0.99 & 1098.3 & 314.1 & 1.01 \\
\hline 65 x ICMP96132 & 163.6 & 26.4 & 0.96 & 715.2 & 285.2 & 0.85 \\
\hline 65 x ICMP93191 & 183.3 & 27.8 & 0.97 & 826.6 & 256.7 & 0.98 \\
\hline $65 \times$ MCNELC & 99.5 & 26.8 & 0.83 & 616.1 & 202.0 & 0.95 \\
\hline 85 x ICMP89410 & 157.8 & 35.1 & 0.89 & 703.6 & 342.2 & 0.73 \\
\hline 85 x ICMP96132 & 177.4 & 37.5 & 0.90 & 872.7 & 280.4 & 0.96 \\
\hline 85 x ICMP93191 & 186.0 & 22.2 & 1.00 & 769.8 & 236.6 & 0.98 \\
\hline 85 x MCNELC & 191.4 & 20.8 & 1.02 & 906.1 & 261.5 & 1.01 \\
\hline Average S* & & & $0.97 \mathrm{a}$ & & & $0.97 \mathrm{a}$ \\
\hline LSD & 45.7 & 8.1 & 0.054 & 149.1 & 60.1 & 0.088 \\
\hline
\end{tabular}

S-stress susceptibility index, *Mean $\mathrm{S}$ values in a column with different letter are statistically different

\subsubsection{Molecular breeding method}

This is the modern approach which is more precise and time saving method when compared with conventional breeding including pearl millet breeding for drought tolerance. Based on the fact that PNHI remains a highly complex trait for which a molecular approach can increase precision during the selection process (Vincent et al., 2012). For molecular breeding, the development of recombinant inbred lines (RILs) is needed to link phenotypic data and marker data, and potentially identify QTLs, i.e., genome portions that are related to phenotypic data. Prior to that, the parents used for crossing should comply with a number of characteristics to maximize the chances of discovering RILs. They should be chosen from large number of accessions (Kramer, 1980); have maximum phenotypic contrast (Sinha.1986); have large genotypic contrast(Begg and Turner, 1976); and be similar for certain 
phenotypic traits that can interact with the trait of interest (yield) (Singh,1990); such as time to flowering or photoperiod sensitivity (Vincent et al.,2012) also taken into consideration.

This approach has been used successfully for the identification of terminal drought tolerance QTLs (Yadav et al., 2003), and the introgression of a terminal drought tolerance QTL into the background of the popular pearl millet hybrid HHB67 to create the new hybrid HHB67-improved. This terminal drought tolerance QTL has a major effect, giving over $30 \%$ of the yield variation under terminal drought.

\subsubsection{QTL and Marker assisted selection for drought tolerance}

Most of the physiological traits associated with drought resistance are quantitative in nature (Serraj et al., 2003) which implies that traits controlled by many genes. Therefore, using molecular markers, QTL can be detected in an appropriate population of plants. A locus for any quantitative trait can be mapped as long as polymorphism is observed in the segregating populations under analysis and phenotypic information is available for the lines in the population (Figure2). However, for traits as complex as drought tolerance, the success of the QTL approach is conditioned by the effectiveness of the phenotyping procedure in detecting among recombinant lines repeatable, highly heritable differences that permit the identification of robust QTL(Serraj et al.,2003).

A QTL-mapping approach is currently used at different research centers including ICRISAT to dissect the genetic and physiological basis and apply marker assisted breeding strategies for several traits linked to drought tolerance, including the PNHI and yield components of pearl millet under terminal drought. For terminal drought in pearl millet, several mapping populations have been developed using restriction-fragment length polymorphism (RFLP) skeleton mapping, trait phenotyping (Hash and Witcombe, 1994) and QTL mapping (Yadav et al., 2002). Test crosses of mapping-population progenies, derived from inbred pollinators and from seed parents differing in their response to drought, were evaluated in a range of managed terminal-drought-stress environments to identify individual QTL associated with drought tolerance (Figure 2).

A number of QTL associated with drought tolerance of grain yield and its agronomic and physiological components were identified (Yadav et al., 2002). Some of the identified QTL were common across water-stress environments and genetic backgrounds of the two mapping populations, while others were specific to a particular water-stress environment or genetic background. Interestingly, all the identified QTL contributed to increased drought tolerance through their effect on either increased maintenance of growth or harvest index or both in terminal-drought stress environments. Programmes for marker-assisted backcross transfer of the identified QTL into the elite parent of these mapping populations have been initiated for the improvement of pearl-millet productivity in water-limited environments (Yadav et al., 2002).

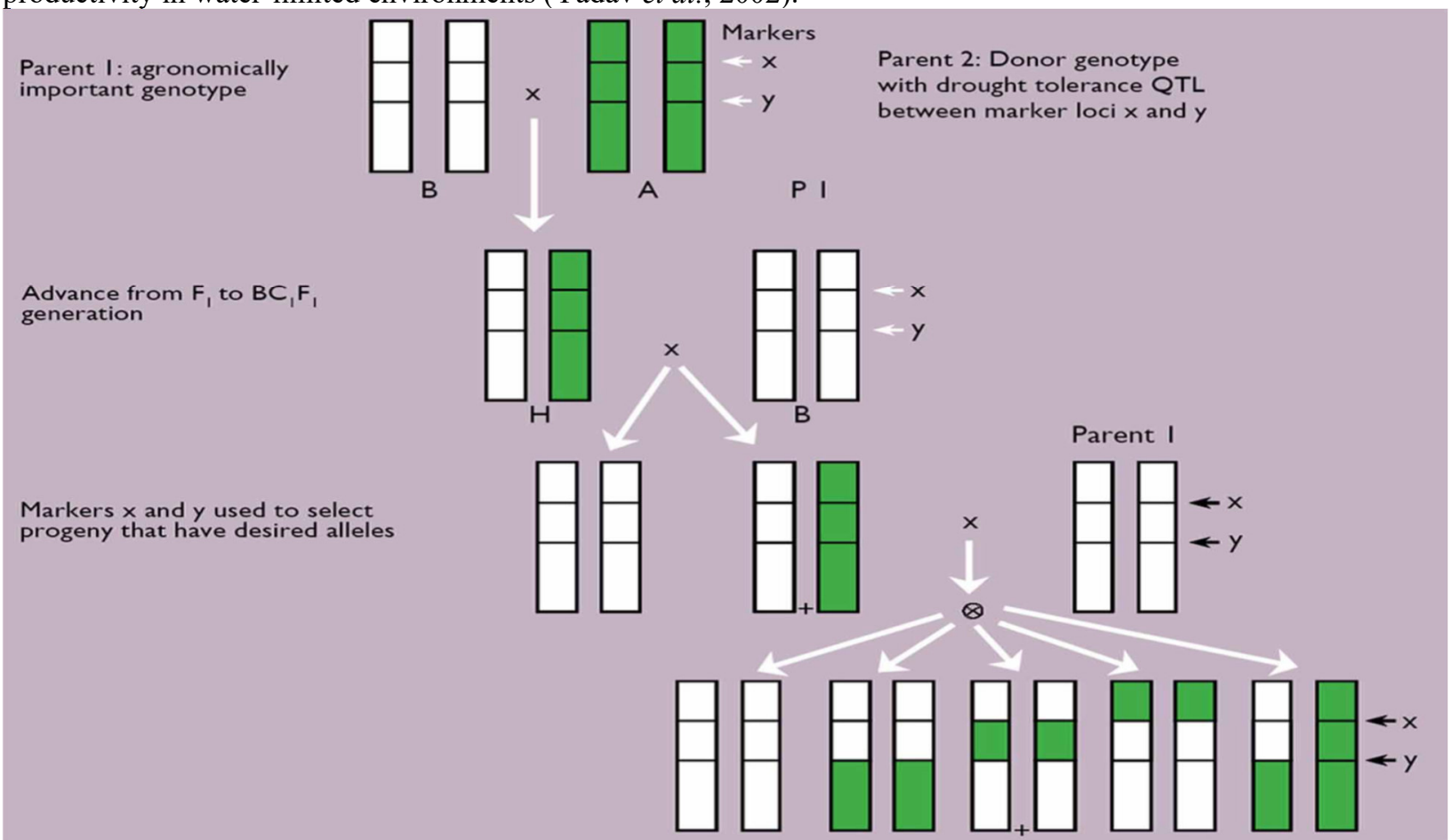

Figure.2 Scheme for marker-assisted backcrossing of desired $(+)$ segregants. A QTL was introgressed after four rounds of marker-assisted backcrossing (Source: Vincent et al., 2012)

\section{CONCLUSION}

Drought stress is a wide spread phenomenon in many areas in which pearl millet is grown. It is the major constraint 
to pearl millet as pearl millet grown in the drier semiarid and arid regions. However, adaptive evolution and natural selection made pearl millet relatively the most drought and heat tolerant among other cereals crops. Like other cereals pearl millet tolerate drought through mechanisms such as drought escape, drought avoidance and drought tolerance. Pearl millet has primary and secondary tillers. Also based on their emergence tillers can be basal and nodal tiller which are important traits that enables pearl millet to tolerate terminal drought. This is due to they emerge from main shoot at different time and compensate the damaged primary tillers flower and grain filling by drought stress. This asynchronous tillering behavior and rapid growth rate allow it to improve rapidly from intermittent drought stress during the early stages of plant development.

Pearl millet has many important phenotypic and physiological characteristics that enable it to adapt and perform under drought stress. These are early flowering and deep rooting characteristics. Early flowering is an important drought escape attribute of pearl millet and enables it to gives yield before drought problems occur. Deep rooting and Lateral root spreading help pearl millet perform very well under drought stress by taking up water deep from the soil. Being C4 plant, physiologically pearl millet withstands high temperature and decrease evaporation by closing stomata which increase their water use efficiency.

Pearl millet breeding for adaptation and performance under drought is on progress using different breeding methods. These breeding methods are conventional and molecular breeding which had being used and also currently under utilization to improve pearl millet for drought tolerant. Conventionally, genotypes that is drought tolerant and result good yield is selected and/ or genetically diverse elites having desirable agronomic traits and dissimilar in drought tolerant potential are crosses to improve yield performance under drought; hence, $66 \%$ heterosis over best parents achieved under stress in grain yield. But in molecular breeding drought tolerant genotype is screened using marker assist selection. Therefore; using these Breeding methods some Pear millet varieties developed for drought prone areas and over 30\% grain yielder variety developed for drought stress areas compared to parents which are locally under production.

\section{REFERANCE}

Begg J.E.(1965).The growth and development of a crop of bulrush millet(Pennisetumtyphoid's $\mathrm{S}$ and $\mathrm{H}$ ). J.Agric.Sci. 65: 341-349.

Begg J. E., Turner N. C. (1976). Crop water deficits. In Advances in agronomy 28:161-217). Academic Press.

Begg J.E. (1980). Adaptation of plants to Water and High temperature stress.), Wiley, New York,pp.33-42.

Bidinger F.R., Mukuru S. Z. (1995)."Threshing percentage a sanindicator of terminal drought stress in sorghum, "in Proceedings of the Eighth EARSAM Regional Workshop on Sorghum and Millets, eds S.Z. MukuruandS. B. King(Patancheru: ICRISAT), 27-35.

Bidinger F.R., Mahalakshmi V., Rao G.D.P. (1987b). Assessment of drought resistance in pearl millet. II. Estimation of genotype response to stress. Aust J Agric Res 38:49-59

Bidinger F.R., Witcombe J.R. (1989). Evaluation of specific drought avoidance traits as selection criteria for improvement of drought resistance. In: Baker FWG (ed) Drought resistance in cereals. CAB International, Wallingford, UK, pp 151-164

Bidinger F.R., Chandra S., Mahalakshmi V. (2000) Genetic improvement of tolerance to terminal drought stress in pearl millet (Pennisetum glaucum (L.) R. Br.). In: Ribaut, J.-M. and Poland, D. (eds) Molecular Approaches for the Genetic Improvement of Cereals for Stable Production in Water-limited Environments. Proceedings of a Strategic Planning Workshop Held at CIMMYT, El Batan, Mexico, 21-25 June 1999. CIMMYT, El Batan, Mexico DF, pp. 59-63.

Bidinger F.R., Lakshmi,M., Talukdar B.S., Alagarswamy G. (1981). Improvement of drought resistance in pearl millet.

Bidinger F.R., Mahalakshmi V., Rao GDP (1987a) Assessment of drought resistance in pearl millet [Pennisetum americanum (L.) Leeke]. 1 Factors affecting yield under stress. Aust J Agric Res 38:37-48

Chopart J.L. (1983). Étudedusys- tèmeracinairedumil(Pennisetum typhoid's) dansunsolsableux du Sénégal. Agron.Trop. 38, 37-51.

Clerget B., Dingkuhn M., Chantereau J., Hemberger G., Louarn G., Vaksmann M. (2004). Does pan- icle initiation in tropical sorghum depend on day-to-day change in photoperiod? Field Crops Res. 88, 21-37.

Craufurd P.Q., Bidinger F.R. (1988). Effect of the duration of the vegetative phase on crop growth, development and yield in two contrasting pearl millet hybrids. J.Agric.Sci. 110, 71-79.

Craufurd P.Q., Bidinger F.R. (1989). Potential and realized yield in pearl millet (Pennisetum americanum) as influenced by plant population density and life-cycle duration. Field Crops Res. 22, 211-225.

Do F., Daouda O.S., Marini P. (1989). Etude agrophysiologiquedes mécanismes derésistance dumilàlasé cheresse. Revue Reseau Ameliorationdela Production Agricoledu Milieu Aride 1, 57-74.

FAO, ICRISAT (1996). The world sorghum and millet economies: facts, trends and outlook. Food and Agricultural Organization of the United Nations (FAO), Rome, Italy, and International Crops Research Institute for the Semi Arid Tropic(ICRISAT), Patancheru, AP, India 
Frova C., Krajewski P., di Fonzo N., Villa M., Sari-Gorla M. (1999). Genetic analysis of drought tolerance in maize by molecular markers. 1. Yield comp. Theor Appl Genet 99:280-288

Fussell L.K., Bidinger F.R., Bieler P. (1991). Crop physiology and breeding for drought tolerance: research and development. Field Crops Res 27:183-199

Gaff D.F.(1980) . In Adaptation of plants to water and High temperature stress 9eds ,Wiley, New York,pp.207230.

Hash C.T., Witcombe J.R. (1994). Pearl millet mapping populations at ICRISAT. In: Witcombe, J.R. and Duncan, R.R. (eds) Use of Molecular Markers in Sorghum and Pearl Millet Breeding for Developing Countries. Overseas Develop. Administration, London, pp. 69-75.

Henson I.E., Mahaklakshmi V. (1985). Evidence for panicle control of stomatal behav- ior in water-stressed plants of pearl millet. Field Crops Res. 11, 281-290.

Jambunathan R., Subramanian V. (1988). "Grain quality and utilization in sorghum and pearl millet,"inWorkshopon Biotechnology for Tropical Crop Improvement, (Patancheru: ICRISAT), 1330-1339.

Kouressy M., Niangado O.,Vaksmann M., Reyniers F.N.(1998)."Étude dudéveloppement dun sorghophotopériodique,"in Le Futurdes Céréales Photopériodiques pourune Production Durableen Afrique Tropicale Semi-Aride, edsL. Bacci and F.N.Reyniers (Florence: CeSIA Accademiadei Georgofili), 59-75.

Kowal J. M., Kassam A .H. (1978). Agricultural Ecology of Savanna. Oxford University Press Oxford. 403 pp

Krame P.J. (1980). In linking Research to crop production, . planum Press, New York., pp.51-62

Levitt J.(1972).Responses of Plants to Environmental Stresses,Academic Press, New York

Ludlow M.M., Muchow R.C. (1990). A critical evaluation of traits for improving crop yields in water-limited environments. Adv Agron 43:107-153

Mahalakshmi V., Bidinger F. R. (1985). Flowering response of pearl millet to water stress during panicle development. Ann.Appl.Biol. 106, 571-578..

Mahalakshmi V., Bidinger F.R., Raju D.S. (1987). Effect of timing of water deficit on pearl millet (Pennisetum americanum). Field Crops Res 15:327-339

Mohan M., Nair S., Bhagwat A., Krishna T.G., Yano M. (1997). Genome mapping, molecular markers and markerassisted selection in crop improvement. Mol Breed 3:87-103

Payne W.A. (1997). Managing yield and soil water use of pearl millet in the Sahel. Agron.J. 89, 481-890.

Payne W.A., Wendt C.W., Lascano R.J. (1990).Root zone water balances of three low-input millet fields in Niger, West Africa. Agron. J. 82, 813-819.

Prioul J.L, Quarrie S., Causse M., de Vienne D. (1997). Dissecting complex physiological functions through the use of molecular quantitative genetics. J Exp Bot 48:1151-1163

Quarrie S.A., Stojanovic J., Pekic S. (1999). Improving drought resistance in small-grained cereals: a case study, progress and prospects. Plant Growth Reg 29:1-21

Ram N., Sheoran K., Sastry C.V. S. (1999). Radiation efficiency and its efficiency in dry biomass production of pearl millet cultivars. Ann. Agric.Res. 20, 286-291.

Richards R.A. (1996). Defining selection criteria to improve yield under drought. Plant Growth Reg 20:157-166

Rooney L. W., McDonough C. M. (1987). "Food quality and consumer acceptance in pearl millet," in Proceedings of the International Pearl Millet Workshop, 7-11, eds J. R. Witcombe and S. R. Beckerman (Patancheru: ICRISAT), 43-61.

Serraj R., Bidinger F.R., Chauhan Y.S., Seetharama N., Nigam S.N., Saxena N.P. (2003) . Management of Drought in ICRISAT Cereal and Legume Mandate Crops International Crops Research Institute for the Semi-Arid Tropics, Patancheru, India

Shashidhar v.r., Ankegowda S.J., Kulkarni M.J., Srinivas M.N., Prasad T.G.,Nagalakshmi U., devendra R., Curr.Sci.(2000).78, 786-789. Sahara in West Africa. FAO/UNESCO/WM0 interagency project on climatology, FAO, Rome

Singh B.R., Singh D.P. (1995). Agronomic and physiological responses of sorghum, maize and pearl millet to irrigation. Field Crops Res. 42, 57-67.

Singh R.P. (1990). Curr. Pract.Dryland resour.Technol.,5,117-136.

Sinha S.K. (1986) .In Approaches for incorporating Drought and salinity resistance in crop plants,pp.56-86.

Squire G.R. (1979).The response of the stomata of pearl millet (Pennisetumtyphoid's $\mathrm{S}$ and H)to atmospheric humidity. J. Exp.Bot. 30, 925-933.

Squire G.R., Ong C.K., Montecito J.L. (1987).“Crop growth in semi-arid environments,” in Proceedings of the International PearlMilletWorkshop,7-11, eds J.R.Witcombe and S.R. Beckerman (Patancheru:ICRISAT),219-231.

Tanksley S.D. (1993). Mapping polygenes. Annu Rev Genet 27: 205-234

Turner N. C. (1979). In stress physiology in crop plants Wiley, New York, ,pp.343-372.

Turner N.C. (1997). Further progress in crop water relations. Adv Agron 50:293-338

Turner N.C., Aust. J. (1986). Plant Physiol, 13,175-190. 
Vadez V., Kashiwagi J., Krishnamurthy L., Serraj R., Sharma K., Devi J. (2005). "Recent advances in drought research at ICRISAT: using root traits and rd29a:DREB1Ato increase water use and water use efficiency in drought-prone areas,": The 2ndInternational Conference on Integrated Approaches to Sustain and Improve Plant Production Under Drought Stress, (Rome, Italy)

Van Oosterom E.J., Mahalaksh mi V., Bidinger F.R., Rao K.P. (1996b). Effect o water availability and temperature on the genotype- by-environment interaction of pearl millet in semi-arid tropical environments. Euphytica 89, 175-183.

Van Oosterom E.J.,Whitaker M. L., Weltzien R.E.(1996a). "Integrating genotype by environment interaction analysis, characterization of drought patterns, and farmer preferences to identify adaptive plant traits in pearl millet,"in: Plant Adaptation and Crop Improvement eds M.Cooperand G.L.Hammer (Wallingford: CAB International), 383-402.

Van Oosterom, E.J., O’leary, G.J., Carberry, P.S. and Craufurd, P.Q., 2002. Simulating growth, development, and yield of tillering pearl millet. III. Biomass accumulation and partitioning. Field Crops Research, 79(2-3), pp.85-106.

Vincent V. Tom H., Francis R. B., Jana K. (2012). Phenotyping pearl millet for adaptation to drought. Plant physiology $3: 386$

Yadav O. P. (2008). Performance of landraces, exotic elite populations and their crosses in pearl millet (Pennisetum glaucum) in drought and non-drought conditions. Plant Breeding. 127: 208-210

Yadav O.P., Weltzien-Rattunde E., Bidinger F.R., Mahalakshmi V. (2000). Heterosis in landrace-based top cross hybrids of pearl millet Across arid environments. Euphytica 112, 285-295

Yadav R.S., Bidinger F.R., Hash C.T., Yadav Y.P., Yadav O.P., Bhatnagar S. K. (2003) . Mapping and characterization of QTL $\times$ E inter- actions for traits determining grain and st over yield in pearl millet. Theory. Appl. Genet. 106, 512-520.

Yadav R.S., Hash C.T., Cavan G. P., Bidinger F.R., Howarth C. J. (2002). Quantitative trait loci associated with traits determining grain and stover yield in pearl millet under terminal drought stress conditions. Theory.Appl. Genet. 104, 67-83. 